\title{
Laparoscopic Cholecystectomy Optimization: Partial Incision of Falciform Hepatic Ligament
}

\author{
DOI: $10.17691 / \mathrm{stm} 2017.9 .2 .17$
}

Received October 12, 2016

V.P. Gorpinyuk, Head of Endoscopy and Minimally Invasive Surgery Department ${ }^{1}$;

G.V. Fomov, MD, PhD, Associate Professor, Department of Surgery with Oncology Cycle; ;

V.V. Zvyagintsev, MD, PhD, Surgeon, Endoscopy and Minimally Invasive Surgery Department';

A.S. Mukhin, MD, DSc, Professor, Head of the Surgery Department, Faculty of Doctors' Advanced Training ${ }^{3}$

${ }^{1}$ Republican Clinical Hospital, 33 Mira St., Tiraspol, 3300, Pridnestrovian Moldavian Republic;

${ }^{2}$ T.G. Shevchenko Transdniestrian State University, 128, 25 October St., Tiraspol, 3300,

Pridnestrovian Moldavian Republic;

${ }^{3}$ Nizhny Novgorod State Medical Academy, 10/1 Minin and Pozharsky Square, Nizhny Novgorod, 603005,

Russian Federation

The aim of the investigation was to develop an optimization technique for laparoscopic cholecystectomy and the prevention of intraoperative complications.

Materials and Methods. Among 393 laparoscopic cholecystectomies performed in 2012, 6 cases had a minor intraoperative complication: liver capsule rupture in gallbladder traction. To prevent the complication, an original technique was developed: partial incision of falciform hepatic ligament. The technique was later used in laparoscopic gallbladder surgeries in 57 patients in 2013-2015.

Results. The survey carried out enabled to distinguish a characteristic group to suspect complication risk, or increased risk factors of liver capsule rupture. For prevention purposes, 57 of 1,055 patients underwent partial incision of falciform hepatic ligament. The technique enables to enhance the right lobe mobility that makes it possible to perform an adequate gallbladder traction and avoid liver capsule rupture, improve the imaging of Calot's triangle elements in non-mobile gallbladder, in limited liver mobility, in gallbladder position anomalies and the attachment anomalies of falciform and round ligaments of the liver.

Conclusion. The suggested technique of falciform ligament incision enables to avoid complications in the form of liver capsule rupture in complex cases, to reduce traumatism, blood loss in laparoscopic cholecystectomy, to enhance the operation availability and safety.

Key words: laparoscopic cholecystectomy; liver capsule bursting; incision of falciform ligament of liver.

Gallstones are revealed in $15-20 \%$ of world population. About half of patients do not observe any cholelithiasis symptoms, calculi in the gallbladder are found when the patients are being examined for other diseases. In the rest patients cholelithiasis is accompanied by a clinical presentation, occasionally with complications, and requires sparing surgical intervention [1]. In abdominal surgery, laparoscopic cholecystectomy (LCE) has spread widely, the advantages of endoscopic surgery being evident [2].

Laparoscopic cholecystectomy, as any invasive procedure, has its complications, which can be divided into two groups: minor intra-operative complications that neither lead to the operation lengthening, nor make a postoperative period change; and major complications requiring additional procedures within a surgery can result in disability and may be life-threatening [3]. The main causes of intra-operative complications in LCE are pathological changes in the operation area, anatomical anomalies and technical errors of preparation.

One of preparation errors is incorrect gallbladder traction, which can be due to two factors.
The first factor is insufficient surgeon's experience, the second one is limited motility of the liver and gallbladder. Due to these factors the applied standard preparation techniques do not always enable to adequately image the gallbladder neck. To simplify the identification of Calot's triangle, some authors suggest using 30-degree optics [4], others - changing standard ports [5]. Operative interventions are to be performed in specialized inpatient departments. In addition to this, the following things are also significant to prevent intra-operative complications in LCE: the experience of a surgical team, early surgery of patients with acute calculous cholecystitis, as well as the use of a plasma scalpel in specific cases.

However, in a number of cases, the application of the suggested techniques does not help avoid some intraoperative complications, which are likely to occur in practice of any surgeon.

The aim of the investigation was to develop an optimization technique for laparoscopic cholecystectomy and the prevention of intraoperative complications.

Materials and Methods. We studied the findings

For contacts: Grogory V. Fomov, e-mail: grim333@list.ru 
of 393 LCE performed in Tiraspol Republican Clinical Hospital (Transdniester) within the year of 2012. 6 cases $(1.6 \%)$ had a minor intra-operative complication: liver capsule rupture in gallbladder traction. A thorough analysis of the complication arisen showed liver capsule bursting to result from gallbladder traction at its fundus, at the place the round and falciform ligaments of the liver are attached, resulting in bleeding, which required hemostasis (additional electro-coagulation) in all the cases. There were found the following factors resulting in liver capsule bursting: liver enlargement and thickening (chronic hepatitis manifestation): 3 cases, gallbladder location anomaly (medial location of the gallbladder): 1 case, atypical attachment of the round and falciform ligaments of the liver (close to the gallbladder): 1 case, destructive enlarged gallbladder: 1 case.

According to the findings of the study, a group of characteristics was distinguished, which enabled to suspect the risk of complications, or increased risk factors of liver capsule bursting. The factors are as follows: enlarged liver, thickening hepatic structure, gallbladder location anomaly, attachment abnormalities of the round and falciform liver ligaments.

In the following years (2013-2015) we performed 1,055 LCE. 57 patients were found to have the abovementioned risk factors, and due to these factors, proper gallbladder traction was impossible. Such patients were decided to be performed partial incision of falciform hepatic ligament to prevent liver capsule bursting.

Group 1 included 6 retrospective cases, group 2 involved 57 patients.

Group 1 consisted of female patients, their mean age being $53.7 \pm 2.4$ years. The diagnosis in 3 patients was phlegmonous calculous cholecystitis, in 2 - chronic calculous cholecystitis, and in 1 patient - gangrenous calculous cholecystitis.

Group 2 involved 54 female and 3 male patients, mean age of females was $52.2 \pm 2.3$ years, and mean age of men was $58.6 \pm 2.1$ years. The diagnosis in 8 patients

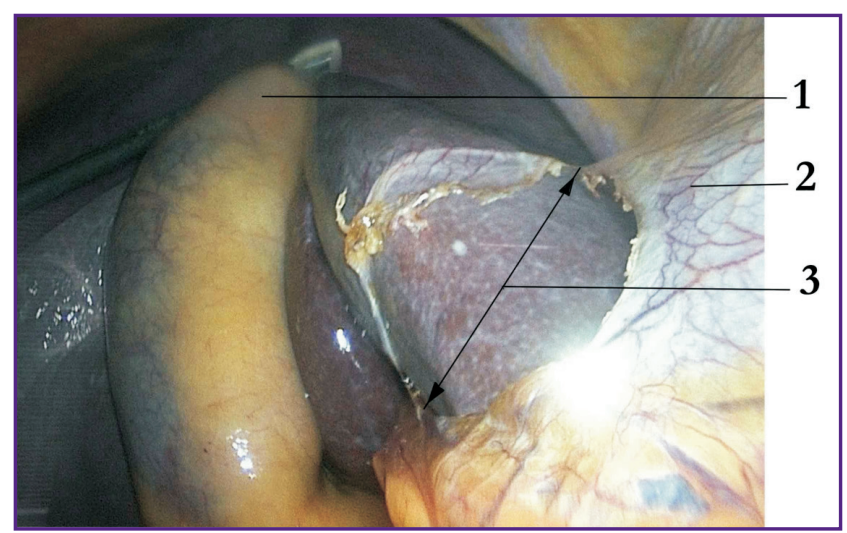

Figure 1. Incised falciform ligament:

(1) gallbladder; (2) falciform liver ligament; (3) incised area of the falciform ligament of the second group was phlegmonous calculous cholecystitis, 3 patients were diagnosed gangrenous calculous cholecystitis, and 46 patients had chronic calculous cholecystitis. 23 patients had abnormally located gallbladder, 10 patients were found to have the attachment anomaly of the round and falciform liver ligaments, 11 patients had destructive and enlarged gallbladder, 13 patients had enlarged and thickened liver.

The study was carried out in accordance with the Declaration of Helsinki (adopted in June 1964, Helsinki, Finland and revised in October 2000, Edinburgh, Scotland) and was approved by the Ethics Committee of Republic Clinical Hospital. All patients gave their written informed consent.

All group 2 patients underwent partial incision of falciform hepatic ligament.

Results. Partial incision of falciform ligament (Figure 1) consisted in the following: after entering the abdominal cavity, the gallbladder fundus was seized, traction being performed, and two characteristics were estimated: tension degree at the liver's anterior border, as well as the round and falciform ligaments, and the possibility to adequately image the gallbladder neck in the present traction.

In cases with a combination of increased risk factors, excess tension of the liver capsule, the round and falciform ligaments, and impossible adequate image of the gallbladder neck, a decision was made to incise falciform liver ligament. The falciform ligament incision was begun by leaving $0.5-1.0 \mathrm{~cm}$ on the liver surface, and by shifting $2.0-3.0 \mathrm{~cm}$ from the place it attaches the round ligament along the diaphragm surface (See Figure 1). The procedure is carried out using an electric hook through an epigastric trocar, a cutting mode being preferable. The technical decision significantly enhanced the right hepatic lobe mobility that enabled to perform an adequate traction and imaging of the gallbladder in all cases. A patent for invention was obtained [6].

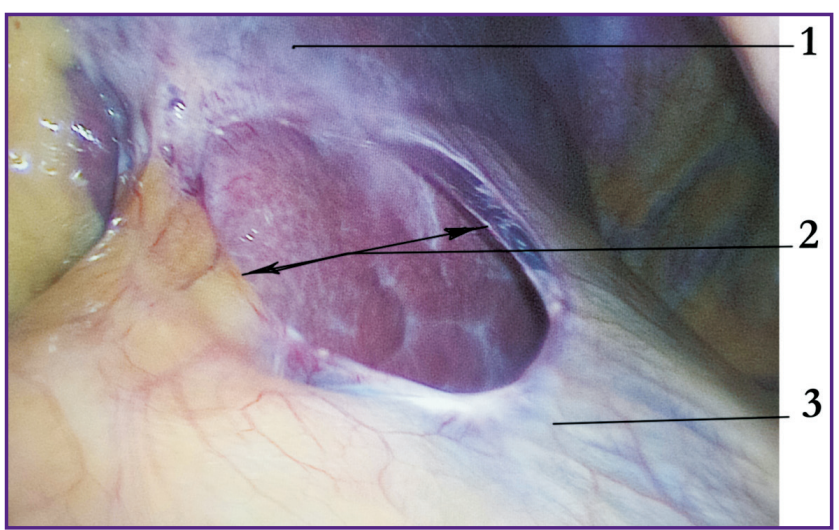

Figure 2. Appearance of incised ligament 1 years after the surgery:

(1) right hepatic lobe; (2) incised area of the falciform ligament; (3) falciform ligament 
According to the risks analyzed, all 57 patients of group 2, who were suspected the risk of the liver capsule rupture in test gallbladder traction, underwent falciform ligament incision to prevent the liver capsule rupture.

As a result of the procedure application, within the period of 2013-2015, the operated patients had no complications in the form of liver capsule rupture. The postoperative period being uneventful, all the patients were discharged on 5 or 6 postoperative days. Their condition being satisfactory, the stitches were taken out on day 5-6. The late postoperative period was also uneventful.

Figure 2 shows the falciform ligament incision in a 42-year-old female patient $M$. She underwent laparoscopy for gynecological pathology a year after the surgery. The line of the incised ligament is well epithelized, neither adhesions nor scars being observed in the ligament incision area.

Conclusion. Liver enlargement and thickening, anomalously located gallbladder, attachment anomalies of the round and falciform ligaments can be referred to the factors of possible liver capsule rupture in laparoscopic cholecystectomy. The technique of falciform ligament incision enables to avoid complications in the form of liver capsule rupture in complex cases. It enhances the gallbladder imaging and does not require the introduction of additional trocars and a retractor. The technique is allowable in any inpatient departments, where laparoscopy is available, since it requires no extra instruments, and is carried out using standard approaches.

Study Funding. The study was not funded by any sources.

Conflicts of Interest. The authors have no conflicts of interest related to the present study.

\section{References}

1. Fedorov I.V., Sigal E.I., Odintsov V.V. Endoskopicheskaya khirurgiya [Endoscopic surgery]. Moscow: GEOTAR-MED; 2001; 351 p.

2. Dadvani S.A., Vetshev P.S., Shulutko A.M., Prudkov M.I. Zhelchnokamennaya bolezn' [Cholelithiasis]. Moscow: Vidar-M; 2000; 139 p.

3. Timerbulatov M.V., Khafizov T.N., Senderovich E.I. Surgical correction of early postoperative complications after laparoscopic cholecystectomy. Endoskopicheskaya khirurgiya 2010; 16(1): 25-27.

4. Gallinger Yu.I., Karpenkova V.I. Laparoscopic cholecystectomy: the experience of 3165 operations. Endoskopicheskaya khirurgiya 2007; 13(2): 3-7.

5. Shamirzaev B.N., Achilov Sh.D. Reduction means of complications of laparoscopic cholecystectomy in patients with acute cholecystitis. Endoskopicheskaya khirurgiya 2009; 15(4): 18-21.

6. Gorpinyuk V.P., Fomov G.V., Zvyagintsev V.V. Sposob laparoskopicheskoy kholetsistektomii [Technique of laparoscopic cholecystectomy]. Patent MYu PMR 472. 2015. 